\title{
Применение геохимических индикаторов для определения генезиса сильвинитов Тюбегатанского месторождения
}

\author{
Н.Е. Молоштанова, Г.А. Исаева \\ Пермский государственный национальный исследовательский универси- \\ тет, 614990, Пермь, ул. Букирева, 15. E-mail: mineral@psu.ru \\ (Статья поступила в редакциию 9 февраля 2015 г.)
}

\begin{abstract}
Приведены результаты изучения соляных пород продуктивного пласта Нижний 2 Тюбегатанского месторождения калийных солей. Отмечено, что исследованные отложения являются перекристаллизованными, о чем свидетельствуют их структурно-текстурные особенности. На основании рассчитанных геохимических показателей - бром-хлорного коэффициента и рубидий-калиевого отношения сделаны выводы о вторичном происхождении некоторых слоев, сложенных сильвинитом из карналлитовых пород. Показано, что условия формирования сильвинитов пласта Нижний 2 близки породам Карлюкского месторождения и пестроокрашенным сильвинитам пласта «Б» Верхнекамского месторождения.

Ключевые слова: сильвинит, каменная соль, карналлит, Тюбегатанское месторождение, рассол, бромхлорный коэффициент, рубидийкалиевое отночение.
\end{abstract}

DOI: $10.17072 /$ psu.geol.27.55

\section{Введение}

Следует отметить три главных направления современной геохимии. Первое из них, как отмечал В.И. Вернадский, охватывает проблемы поисков различных видов полезных ископаемых в целях расширения минерально-сырьевой базы; второе связано с наиболее актуальной проблемой современности - охраной окружающей среды; третье - с проблемой происхождения химического состава нашей планеты.

Кроме того, геохимические методы позволяют уточнить генезис многих полезных ископаемых, установить генетические типы различных осадочных пород, в том числе выделить первичноседиментационные и вторичные процессы кристаллизации солей.
Изоморфное замещение микроэлементами макроэлементов в природных соединениях можно использовать как эффективный и чувствительный индикатор, позволяющий решать некоторые вопросы условий образования и истории развития отдельных минералов. К таким микроэлементам относятся бром и рубидий в минералах солей хлоридного состава. Бром изоморфно замещает хлор, а рубидий калий в сильвине и карналлите.

В геологии калийных и калийномагниевых солей геохимия брома и рубидия применяется весьма широко как отечественными исследователями, так и за рубежом [13, 14]. Многолетний опыт работы в данном направлении отражен в работах М.Г. Валяшко и его последователей, в том числе в тематическом сборнике статей [2], посвященном закономерностям

(C) Молоштанова Н.Е., Исаева Г.А., 2015 
распределения брома в соляных месторождениях, где обобщен мировой опыт.

В настоящей работе рассматривается применение геохимических показателей распределения брома и рубидия в калийных отложениях Тюбегатанского месторождения и их сравнительная характеристика с аналогами из других месторождений для решения генетических задач.

\section{Характеристика месторождения}

Тюбегатанское месторождение калийных солей расположено на границе Узбекистана и Туркменистана и относится к Среднеазиатскому соляному бассейну. В тектоническом отношении территория месторождения приурочена к северозападному крылу Тюбегатанской брахиантиклинали. Калийные породы Тюбегатанского месторождения содержатся в составе трех горизонтов галитовой (соленосной) подсвиты гаурдакской свиты $\left(\mathrm{J}_{3} \mathrm{gd}\right)$ киммеридж-титонского возраста (рис. 1) и относятся к верхнеюрской галогенной формации.

Соляные отложения сложены каменной солью и сильвинитом и перекрыты верхнеюрскими, нижнемеловыми и четвертичными терригенными (с редкими пачками известняков) породами. Промышленные содержания $\mathrm{KCl}$ установлены

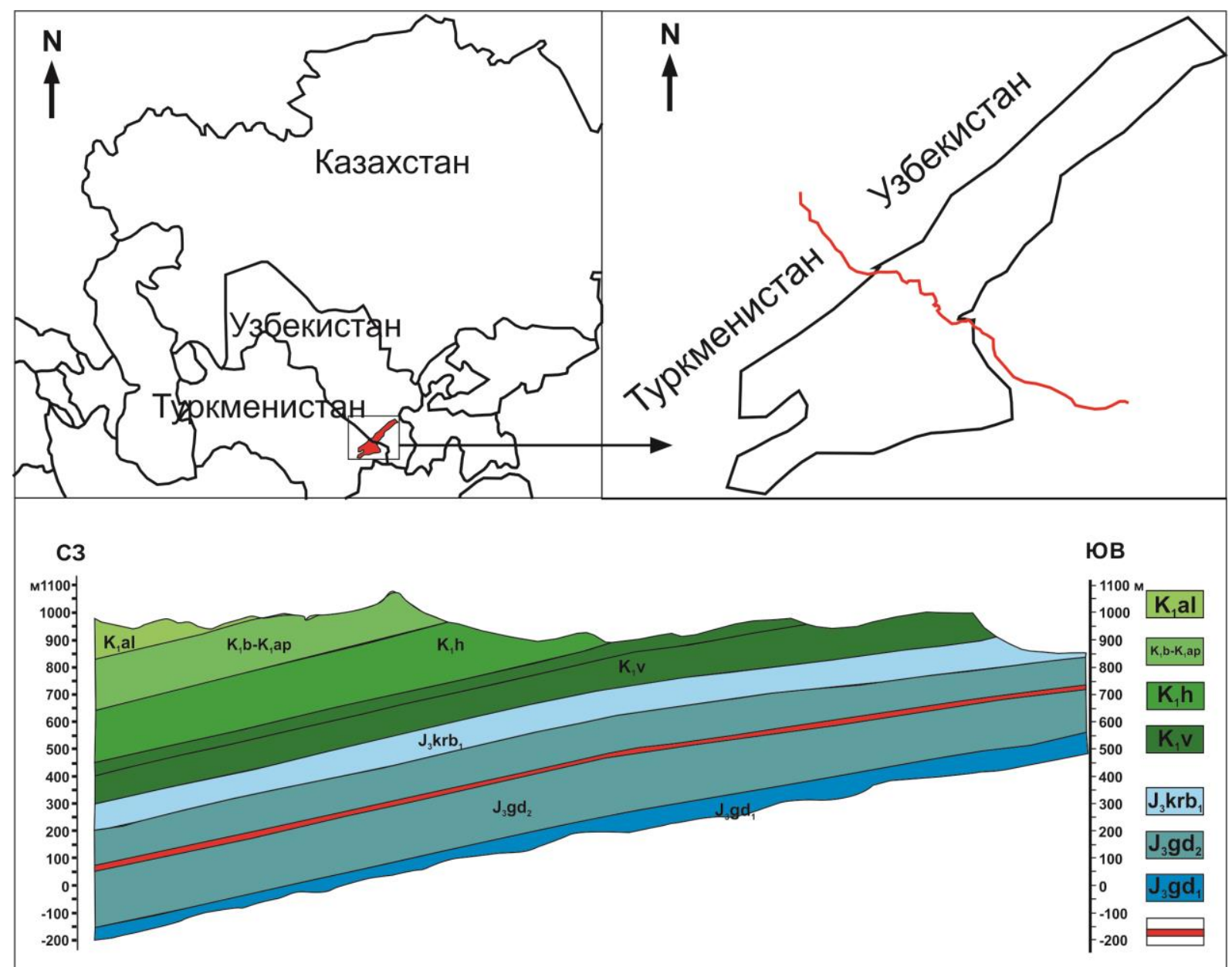

Рис. 1. А - обзорная карта Средней Азии, Б - схематическая карта Тюбегатанского месторождения в контуре подсчета запасов, В - геологический разрез месторождения (условные обозначения снизу вверх: пласт Нижний 2, верхнеюрские отложения гаурдакской и карабильской свит киммириджского-титонского ярусов; нижнемеловые отложения валанжинского, готтеривского, баррем-аптского и альбского ярусов) 
во втором пласте (Нижний 2) нижнего горизонта и составляют от 15,6 до $50,5 \%$ (среднее - 34,3 \%) при мощности 0,8 до 12,8 м (среднее - 5,65 м) [11]. Запасы калийных солей по категориям $\mathrm{A}+\mathrm{B}+\mathrm{C}_{1}$ coставляют порядка 400 млн т, а по категории $\mathrm{C}_{2}-286$ млн т [10].

Продуктивный подгоризонт подразделяется на два пласта Нижний 2а и Нижний 2б. Соляные породы представлены сильвинитом, каменной солью, галитангидрит-карбонатной и галит-карбонатной породами [7]. Отложения перекристаллизованы, для них характерны круп-
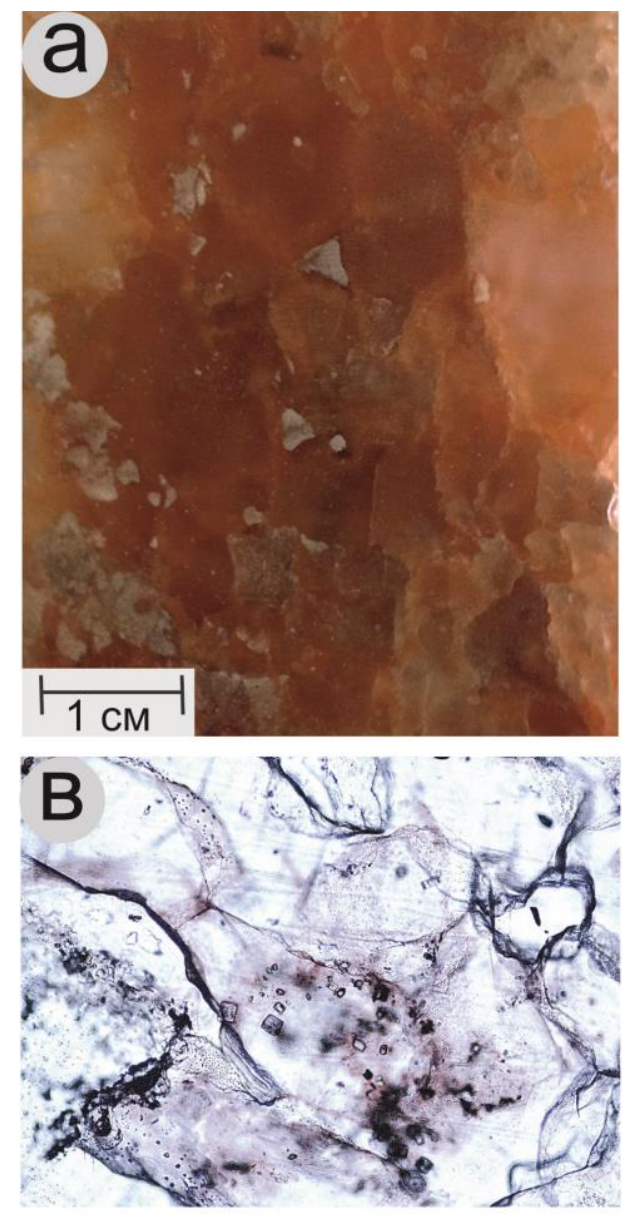

но- и гигантокристаллические структуры и неяснослоистые текстуры, годовые слои не выделяются (рис. 2, а,б). Окраска пород неравномерная, обусловлена распределением гематита и глинисто-карбонатного материала, концентрирующегося в межзерновом пространстве (рис. 2, в,г). Содержание нерастворимого остатка невелико: по данным опробования разведочных скважин колеблется от 0,6 до 3,6 \%. Минералы нерастворимого остатка представлены в основном ангидритом, доломитом, магнезитом, кварцем, хлоритом, иллитом [8].
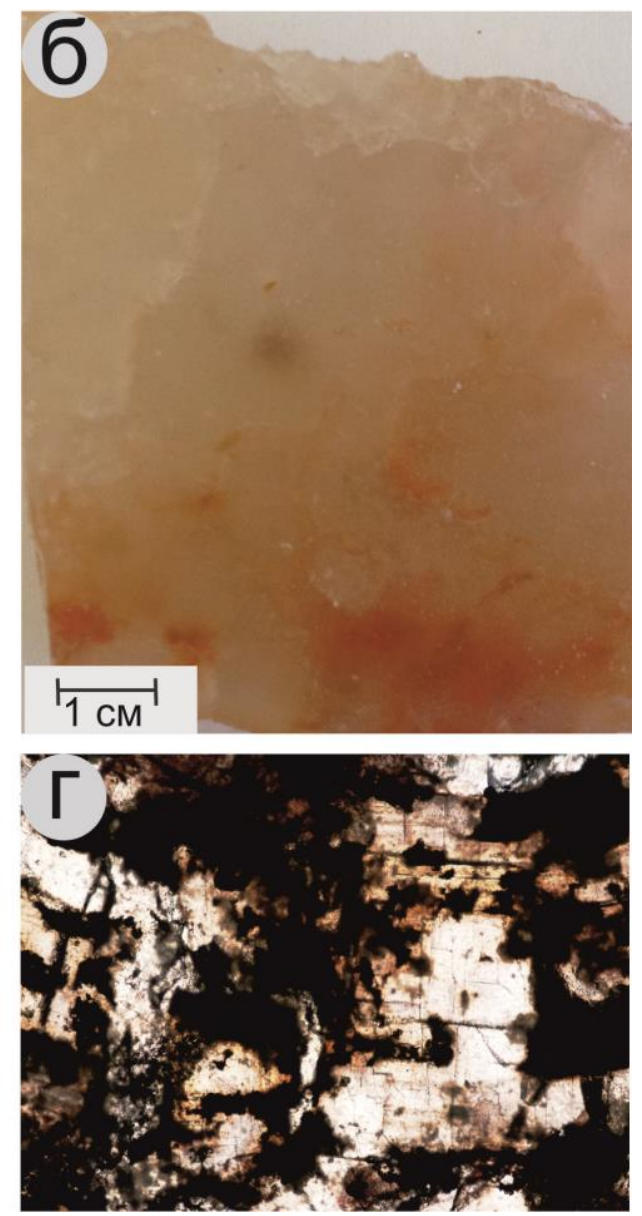

Рис. 2. Фото образиов: а - сильвинит, б - каменная соль; микрофотографии пород в шлифе (увеличение 50 раз): в - ксеноморфные кристалль сильвина и микровключения ангидрита по контуру зерен, г - глинисто карбонатное вещество между кристаллами галита в каменной соли

Считается, что познеюрский солеродный бассейн был связан с открытым морем, а эвапориты верхнеюрской формации являются глубоководными образованиями и их мощность отражает глубину соле- родного бассейна. Отмечается также, что депрессионные структуры, в которых происходило накопление хлоридных солей, приурочены к зонам приразломных прогибов [1]. 
По данным геохимического изучения солей Среднеазиатского бассейна, соляные породы верхнеюрской галогенной формации сильно обеднены бромом [12]. Это связано, по мнению исследователей, с изначально низкими содержаниями брома в рассолах в результате воздействия на них вод континентального стока, десцендентных (образовавшихся за счет ранее разрушенных древних солей и выщелачивания) рассолов и эпигенетических процессов.

\section{Геохимические исследования}

Экспериментальными исследованиями М.Г. Валяшко, Т.В. Мандрыкиной и Н.С. Петровой [4, 5] было установлено, что изменение величины бромхлорного $\left(\mathrm{Br} / \mathrm{Cl} \cdot 10^{3}\right)$ и рубидий-калиевого отношений $\left(\mathrm{Rb} / \mathrm{K} \cdot 10^{4}\right)$ может служить показателями условий кристаллизации и преобразования солей в период диагенетических и катагенетических процессов, протекающих при формировании главных породообразующих минералов соляной толщи.

Для сильвина установлена прямая связь между содержаниями брома и рубидия в процессе кристаллизации из морской воды, а для карналлита характерна обратная корреляция элементов, так как концентрация рубидия снижается от первых кристаллов к последним. Поведение элементов при прогрессирующем осолонении схематически показано на рис. 3 .

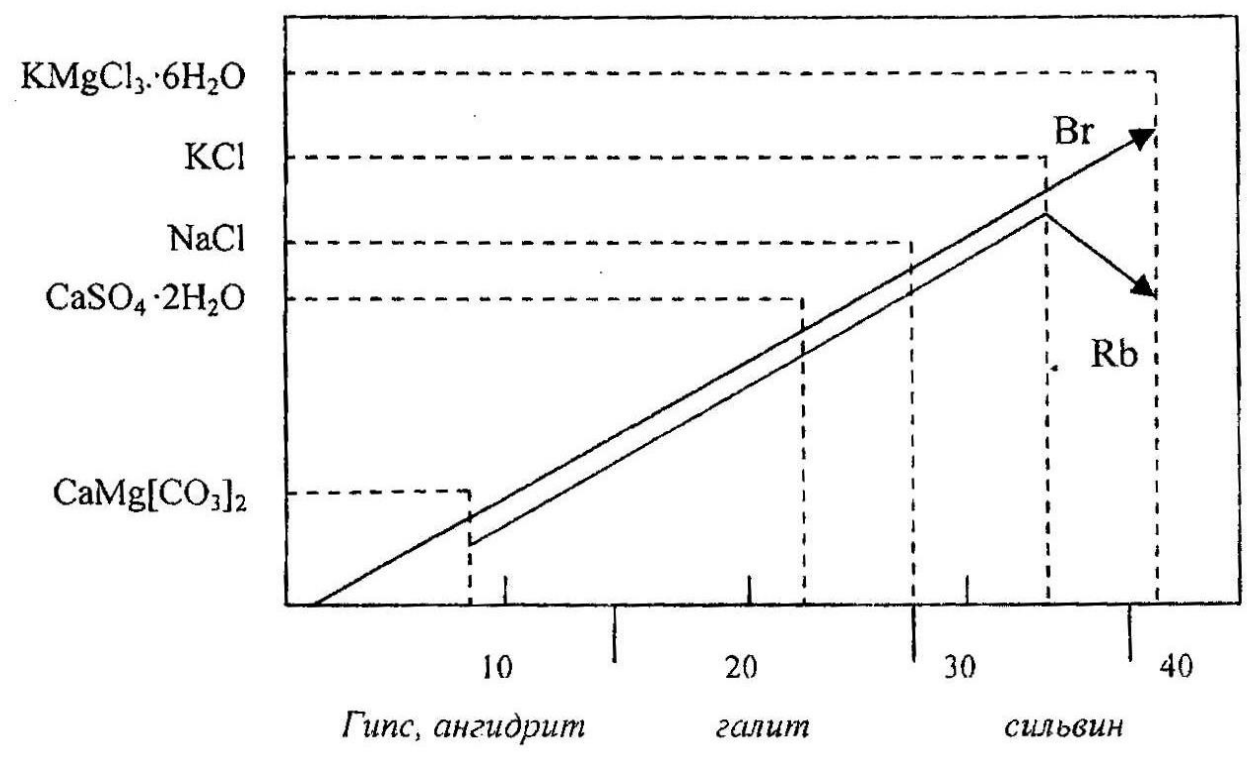

Рис. 3. Концентрация брома и рубидия в эвапоритах при прогрессирующем осолонении бассейна [9]

Существует несколько путей образования сильвина [5].

1. Из сгущающейся морской воды, лишенной сульфат-иона (метаморфизованной). В этом случае от начала до конца кристаллизации содержание брома в кристаллах сильвина будет изменяться от 0,13 до 0,20 мас. $\%, \mathrm{Br} / \mathrm{Cl} \cdot 10^{3}$ составит 2,9 - 4,2. Содержание рубидия в таком сильвине будет колебаться в пределах 0,0017-
0,0053 мас. $\%$, а отношение $\mathrm{Rb} / \mathrm{K} \cdot 10^{4}$ составит $0,32-1,02$.

2. Выделение сильвина за счет растворения первичных карналлитов. Для сильвина будут характерны содержания брома в два раза ниже относительно количества этого элемента в исходном карналлите. Количество рубидия в сильвине может достигать 0,0542 мас.\% и более.

3. Вторичная кристаллизация сильвина из рассолов, возникших при растворении 
первично-седиментационных сильвинитов. При таком способе образования сильвин будет характеризоваться минимальными содержаниями брома и рубидия, при этом количество рубидия может снизиться до следов.

Для сравнения геохимических показателей соляных пород Тюбегатанского месторождения были использованы результаты рентгенофлуоресцентного анализа, выполненного на приборе S8 Tiger (Bruker). Были рассчитаны бромхлорные коэффициенты и рубидий-калиевые от- ношения для 16 проб, в которых были определены содержания рубидия. Показатели нанесены на соответствующие диаграммы для сопоставления с литературными данными по калийным месторождениям хлоридного типа (рис. 3), а также с ранее полученными результатами по сильвинитам Верхнекамского месторождения [9]. Расчеты проведены для сильвинитов из всех слоев пласта Кр-II, полосчатых разностей пласта «А» и пестроокрашенных из пласта «Б».

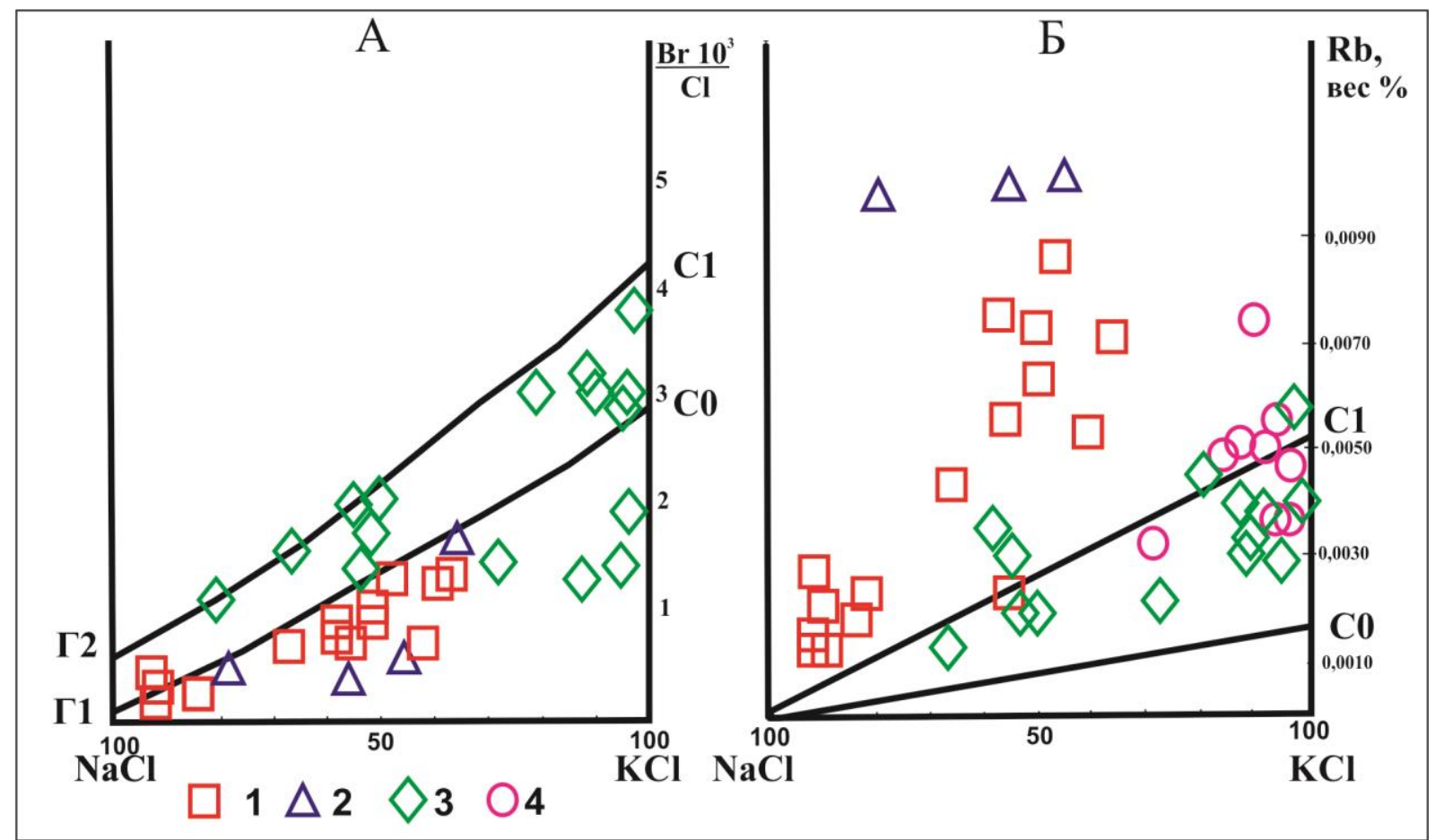

Рис. 3. Шкала нормальных величин геохимических показателей для сильвинитов, выделившихся из морской воды в процессе её сгущения. Геохимические показатели сильвинитов: $A$ бромхлорные коэффициенты; Б-содержание рубидия [4, 5]: 1 - Тюбегатанское месторождение, пласть нІІа и нІІ; 2 - Карлюк, Средняя Азия; 3 - Верхнекамское месторождение, пласты Кр-II и А; 4 - Верхнекамское месторождение, пласт «Б». Г1-С0 - кривая, характеризующуая начало кристаллизации сильвина, Г2-С1 - значения показателя к кониу формирования сильвина

На диаграмме область значений геохимических показателей, характерных для образования сильвинитов из сгущающейся морской воды (первый случай), ограничена кривыми Г1-С0 и Г2-С1. Отчетливо видно, что большая часть фигуративных точек бромхлорных коэффициентов сильвинитов пласта Нижний 2 попадает в область с пониженными от нормальных условий кристаллизации сильвина. Содержания рубидия, напротив, являются повышенными. Такая ситуация характерна для второго пути образования сильвина - из растворившихся карналлитов. Показатели являются наиболее близкими к сильвинитам Карлюкского месторождения, для которого ранее указывалось формирование сильвинитов из первичных 
карналлитов [5]. Сильвиниты продуктивных пластов «Кр-ІІ» и «А» Верхнекамского месторождения относятся к первичноседиментационным образованиям: их геохимические показатели попадают в поле нормальных значений. Исключение составляет пестро-окрашенный сильвинит из пласта «Б», который по распределению рассчитанных показателей сходен тюбегатанским сильвинитам. Примечательно также сходство сильвинитов пласта «Б» с отложениями пластов подгоризонта Нижний 2 по структурно-текстурным особенностям: крупно- и гигантокристаллические структуры, неоднородные, часто пятнистые текстуры.

Таким образом, использование геохимических индикаторов показало, что образование сильвинитов продуктивного пласта Тюбегатанского месторождения происходило в том числе и за счет перекристаллизации их из первичных карналлитов. Это значит, что сгущение морской воды на начальном этапе формирования месторождения происходило до садки калийно-магнезиальных солей, которые затем были растворены под воздействием вторичных процессов. Наличие карналлитовых пластов в Карлюкском и ряде других месторождений Среднеазиатского бассейна, и отсутствие их в Тюбегатанском обусловлено тектоническим фактором, а именно положением и глубиной депрессионных структур, в которых накапливались толщи калийных солей, а также благоприятными условиями для их сохранения при постседиментационном преобразовании пород.

\section{Библиографический список}

1. Бабаев А.Г. Позднепалеозойские эвапориты Средней Азии // Проблемы соленакопления. Новосибирск: Наука, 1977. С. 285289.

2. Борисенков В.И., Валяшко М.Г., Виноградов A.П. $и$ др. Бром в соляных отложениях и рассолах. М.,1976. $455 \mathrm{c}$.

3. Валяшко М.Г. Геохимические закономерности образования месторождений калийных солей. М.: Изд-во МГУ, 1961. 374 с.
4. Валяшко М.Г., Мандрыкина Т.В. Бром в соляных месторождениях как генетический и поисковый признак // Труды ВНИИГа. 1952. Вып. 23. С.108-117.

5. Валяшко М.Г. Петрова Н.С. Использование брома и рубидия в качестве геохимических индикаторов при оценке генезиса калийных солей // Бром в соляных отложениях и рассолах. М.,1976. С. 418-427.

6. Жеребцова И.К. Отношение калия к брому в рассолах выщелачивания - чувствительный гидрохимический индикатор на калийные соли // Бром в соляных отложениях и рассолах. М., 1976 .С. 371-381.

7. Исаева Г.А. Вещественный состав сильвинитов продуктивного пласта Тюбегетанского месторождения калийных солей // Геология и полезные ископаемые Западного Урала / Перм. ун-т. Пермь, 2014. С. 29-33.

8. Исаева Г.А., Молоштанова Н.Е. Минеральный состав нерастворимого остатка сильвинитов Тюбегатанского месторождения // Проблемы минералогии, петрографии и металлогении / Перм. ун-т. Пермь, 2014. C. 55-59.

9. Молоштанова Н.Е., Кропачев А.М. Модель формирования сильвинитов Верхнекамского месторождения калийных солей // Геология и полезные ископаемые Западного Урала / Перм. ун-т. Пермь, 2008 С. 122-128.

10. Кудрямов А.И., Грибков Д.С. Горногеологические условия разработки Тюбегатанского месторождния калийных солей // Рудник будущего. 2010. Вып. 1. С. 1114.

11. Поздеев А.А., Земсков А.Н., Ибрагимов Г.И. Некоторые аспекты освоения Тюбегатанского месторождения калийных солей // Рудник будущего. 2010. Вып. 1. С. 6-10.

12. Попов В.С., Осичкина Р.Г., Касымходжаева У.С. и др. Геохимические особенности верхнеюрской галогенной формации юга Средней Азии // Проблемы соленакопления. Новосибирск: Наука, 1977. С. 291294.

13. Bukowski K., Czapowski G., Karoly S., Babel $M$. Sedimentology and geochemistry of the Middle Miocene (Badenian) salt-bearing succession from East Slovakian Basin (Zbudza Formation) // Evaporates Through Space and Time. 2007. Vol. 285, 247-265. 
14. Rahimpour-Ronab H., Shariatinia Z., Shiemann M.G. Role of rifting in evaporate deposition in the Great Kavir Basin, central
Iran // Evaporates Through Space and Time. 2007. Vol. 285, 69-85.

\title{
Use of Geochemical Indicators to Determine the Genesis of Sylvinite of the Tubegatan Deposit
}

\author{
N.E. Moloshtanova, G.A. Isaeva \\ Perm State University, 15 Bukireva Str., Perm 614990, Russia \\ E-mail:mineral@psu.ru
}

This article presents the results of study of salt rock from productive bed "nizhniy 2 " of the Tubegatan potash deposit located at the southern territory of the Uzbekistan Republic. Analysis of structural and textural features of the studied sediments showed that they were recrystallized. Calculated geochemical indicators, such as bromine-chlorine ratio and rubidium-potassium ratio, confirmed the conclusion about the secondary origin of some sylvinite beds from carnallite strata. It is shown that the formation conditions of the "nizhniy 2" sylvinite bed were similar to those of Karlyuk deposit and to multi-colored sylvinite from bed "B" of the Verkhnekamskoe deposit (Upper Kama potash deposit).

Keywords: sylvinite; salt rock; halite; carnallite; Tubegatan deposit; brine; brominechlorine ratio; rubidium-potassium ratio.

\section{References}

1. Babaev A.G. 1977. Pozdnepaleozoyskie evapority Sredney Azii [Late Paleozoic evaporites of the Central Asia]. In Problemy solenakopleniya. Novosibirsk, Nauka, pp. 285289. (in Russian)

2. Borisenkov V.I., Valyashko M.G., Vinogradov A.P. et al. 1976. Brom v solyanych otlozheniakh i rassolakh [Bromine in the brines and salt sediments]. Moskva, P. 455. (in Russian)

3. Valyashko M.G. 1961. Geohimicheskie zakonomernosti obrazovaniya mestorozhdeniy kaliynyh soley [Geochemical regularities of potash deposits formation]. Moskva, p. 374. (in Russian)

4. Valyashko M.G., Mandrykina T.V. 1952. Brom v solyanykh mestorozhdeniyakh kak geneticheskiy i poiskovyy priznak [Bromine of the salt deposits as genetic and search indicator]. Trudy VNIIGa, 23: 108-117. (in Russian)

5. Valyashko M.G., Petrova N.S. 1976. Ispolzovanie broma i rubidiya $\mathrm{v}$ kachestve geokhimicheskikh indikatorov pri otsenke genezisa kaliynyh soley [The use of bromine and rubidium as geochemical indicators for assessment of the genesis of potash salts]. In Brom v solyanykh otlozheniakh i rassolakh. Moskva, Pp. 418-427. (in Russian)

6. Zherebtsova I.K. 1976. Otnoshenie kaliya $\mathrm{k}$ bromu v rassolakh vyshchelachivaniya - chuvstvitelnyy gidrokhimicheskiy indikator na kaliynye soli [The ratio of potassium to bromine in the leached brines as a sensitive hydrochemical indicator for potash salts]. In Brom v solyanykh otlozheniakh i rassolakh. Moskva, Pp. 371-381. (in Russian)

7. Isaeva G.A. 2014. Veshchestvennyy sostav silvinitov produktivnogo plasta Tubegatanskogo mestorozhdeniya kaliynykh soley [The mineral composition of sylvinite of the productive bed of the Tyubegatanskoe potash deposit]. Proc. conf. Geologiya i poleznye iskopaemye Zapadnogo Urala. Perm, Perm State University, pp. 29-33. (in Russian)

8. Isaeva G.A. Moloshtanova N.E. 2014. Mineralnyy sostav nerastvorimogo ostatka silvinitov Tubegatanskogo mestorozhdeniya [The mineral composition of the insoluble residue of sylvinite of the Tubegatan depos- 
it]. In Problemy mineralogii, petrografii $\mathrm{i}$ metallogenii. Perm, Perm State University, pp. 55-59. (in Russian)

9. Moloshtanova N.E., Kropachev A.M. 2008. Model formirovaniya silvinitov Verkhnekamskogo mestorozhdeniya kaliynykh soley [Model of formation of sylvinite of the Verkhnekamskoye potash deposit]. Proc. conf. Geologya i poleznye iskopaemye Zapadnogo Urala. Perm, Perm State University, pp. 122-128. (in Russian)

10. Kudryashov A.I., Gribkov D.S. 2010. Gornogeologitcheskie usloviya razrabotki Tubegatanskogo mestorozhdeniya kaliynyh soley [Mining and geological conditions of development of the Tubegatan potash deposit]. Rudnik budushchego, Per, 1: 11-14. (in Russian)

11. Pozdeev A.A., Zemskov A.N., Ibragimov G.I. 2010. Nekotorye aspekty osvoeniya Tubegatanskogo mestorozhdeniya kaliynyh soley [Some aspects of development of the Tubegatan potash deposit]. Rudnik budushchego, Perm, 1: 6-10. (in Russian)
12. Popov V.S., Osichkina R.G., Kasymkhodzhaeva U.S. et al. 1977. Geokhimicheskie osobennosti verkhneyurskoy galogennoy formatcii yuga Sredney Azii [Geochemical features of the Upper Jurassic halogen formation of south Central Asia]. In Problemy solenakopleniya. Novosibirsk, Nauka, pp. 291-294. (in Russian)

13. Bukowski K., Czapowski G., Karoly S., Babel $M$. 2007. Sedimentology and geochemistry of the Middle Miocene (Badenian) salt-bearing succession from East Slovakian Basin (Zbudza Formation). Evaporates Through Space and Time. Geological Society, London, Special Publications, 285: 247-265. doi: 10.1144/SP285.14 0305-8719

14. Rahimpour-Ronab H., Shariatinia Z., Shiemann M.G. 2007. Role of rifting in evaporate deposition in the Great Kavir Basin, central Iran. Evaporates Through Space and Time. Geological Society, London, Special Publications, 285: 69-85. doi: 10.1144/SP285.5 0305-8719 